\title{
Research on Economic Evaluation Method of Electric Vehicle Charging Station
}

C. Liu, B. Li

China Electric Power Research Institute, Beijing Electric Vehicle Charging/Battery Swap Engineering and Technology Research Center, Beijing, China

Y.L. Wang

Yinchuan Power Supply Bureau of Ningxia Power Company, Yinchuan, China

L. Xia

China Electric Power Research Institute, Beijing, China

L. Yu

School of Control and Computer Engineering, North China Electric Power University, Beijing, China

N. Ding, X.F. Ma

School of Electrical \& Electronic Engineering, North China Electric Power University, Beijing, China

ABSTRACT: The development of electric vehicle charging station have a directly influence on the promotion of. With large construction of charging station in China in recent years, it's of great importance to establish reasonable charging station construction. According to the graphic appraisal method, we set 12 secondary indicators from profitability, liquidity and financial abilities in this paper. Firstly, we make reasonable index weight by the analytic hierarchy process (AHP). Then get the charging station specific scores in associate with fuzzy comprehensive evaluation method. At last, we take a charging station as an example using the method proposed in this paper.

KEYWORD: electric vehicle; charging station; economics; fuzzy comprehensive evaluation method

\section{INTRODUCTION}

In recent years, with the improvement of living standards, the quantity of motor vehicles in China has grown rapidly. Motor vehicle exhaust pollution has become one of the main sources of pollution in urban atmosphere.

As electric vehicle has many advantages such as energy saving, environmental protection and so on, our government has issued a series of policies to promote the development of electric vehicle industry. And the electric vehicle charging facilities are also building up simultaneously. By the end of 2014, the number of electric vehicles in our country had been more than 120,000 , while the charging station were only 723 ,and the charging pile were 28,000 . In order to promote the healthy development of the electric vehicle industry, the charging and switching facilities need to further construct (X.Q. Wang, 2015).

At present, the electric vehicle charging mainly has three modes: slow-charging, fast-charging and battery replacement. Slow-charging needs too more time. Battery replacement has many problems. Firstly, it cost a lot. Secondly, the type of battery from different manufacturers is different. Last, the ratio of built battery replacement stations is too low (B. Tian. 2012). Correspond with charging mode, the current domestic and foreign electric vehicle charging facilities commercial operation mode is mainly divided into charging pile mode, public charging station mode and battery replacement station mode. Charging pile mode has many advantages such as low power, small area and invests. So it applies to slow charging places such as residential area, parking lots and so on. But the equipment using rate is low. The public charging station mode provides fast charge, slow charge and other services, but need more place, invest and operation cost. Currently, it needs 3,000,000 to build a new charging station. With low car population, the equipment utilization is limited. The charging facilities are generally in the red (M. Lu, X.B, 2010).

At present, it has many analyses about the economy of electric vehicle and charging station in China. In paper (Y. Wang. 2011, T.T. Jiang. 2013, C. $\mathrm{Yu}$. 2010), the authors analyzed the economic model of the electric vehicle market. In paper (C.H. Song. 2013, T. Xu, L. Zhang \& Y.L. Liang. 2011, Y.H. Jin \& X.J. Li. 2012), the authors analyzed the economy of energy consumption technology. In paper, the authors analyzed the economy of charging station construction. In paper (J.L. Fan \& J. Liu. 2014), the authors comprehensive evaluated the charging station.

The above papers evaluate electric charging industry from the economic indicators of energy technology, market investment risk, and comprehensive benefit of charging station, lack of economic evaluation index and method of electric vehicle charging station operation. Therefore, in the process of the electric vehicle development, it is of important to evaluate the economics of electric vehicle charging station for the charging station planning and construction. 


\section{THE ECONOMIC EVALUATION INDEX OF CHARGING FACILITIES OPERATION}

Based on graphic appraisal method (GAM), this paper established the evaluation index of electric vehicle charging station. The evaluation indexes are mainly divided into three categories: charging station profit ability index, refunding ability index, financial viability index. The meaning of each index is shown as follows in Table 1.

(1) Static payback time

Static payback time $(\mathrm{Pt})$ means the time when the project net cash flow of investment is equal to the original total investment.

(2) Return on investment

To calculate Return on investment (ROI), the benefit of an investment is divided by the cost of the investment, and the result is expressed as a percentage or a ratio.

(3) Rate of return on common stock holders' equity

Rate of return on common stock holders' equity (ROE) means the profitability of the project capital.

(4) Internal rate of return

Internal rate of return (IRR) is equal to the rate when the net present value equals to zero.

(5) Net present value

Net present value (NPV) is the difference between the present cash inflow value of expected return and the real outlay. The positive value of NPV means the project can create value for the shareholders is positive. The negative value of NPV means the project will damage the value of the shareholders.

(6) Net annual value

Net annual value (NAV) is equal to all the net cash flow at each share to equivalent uniform annual worth during the calculation period based on the given the discount rate.

(7) Net present value rate

Net present value rate (NPVR) is the ratio of the net present value of the project to the present value of the original investment.

(8) Debt service coverage ratio

Debt service coverage ratio (DSCR) is the annually ratio of funds can be used for debt service to the current the amount of debt service payments during the loan repayment period.

(9) Interest coverage ratio

Interest coverage ratio (ICR) is the ratio of annually pre-tax profits to the interest cost during the loan repayment period.

(10) Asset-liability ratio

Asset liability ratio is the ratio of to the total liabilities to the total amount of assets.

(11) Net cash flow

Net cash flow (NCF) is equal to revenue (cash and cash equivalents inflow) minus the spending. It reflects the enterprises net increase or decrease in net cash and cash equivalent amount in a certain period.

(12) Cumulative surplus funds

Cumulative surplus funds are equal to total current assets minus accounts receivable inventory and cash.

Table 1. The economic evaluation index of charging station.

\begin{tabular}{cc}
\hline First class index & Second class index \\
\hline & Pt \\
ROE \\
charging station & IRR \\
profit ability index & NPV \\
& NAV \\
& NPVR \\
ROI \\
\hline charging station & DSCR \\
refunding ability index & ICR \\
\hline charging station & Asset liability ratio \\
financial viability index & NCF \\
\hline
\end{tabular}

\section{THE ECONOMIC EVALUATION METHOD OF CHARGING FACILITIES OPERATION}

In order to evaluate the reasonable design of charging station, the economic evaluation method of charging facilities operation is proposed in this paper.

\subsection{Fix weight}

In this paper, we adopt the analytic hierarchy process (AHP) to determine the weight of the indexes. The concrete steps are as follows.

(1) Construct the analytic hierarchy

To construct the analytic hierarchy is to decompose the complex problems. It can be divided into the target layer, criteria layer and solution layer according to the mutual and affiliation relationship. Target layer is the goal that the decision maker wants to achieve. Criterion layer is the manner to judge whether the target can be achieved. It can be further divided according to the need. Solution layer is generally the various solution.

(2) Structure judgment matrix

Judgment matrix is to compare with the importance between the factors of the same level aimed at the up level elements. If this layer has f evaluation factors, we can constitute the judgment matrix $E=(e)_{f \times f}$. Generally,

According to with the 1-9 scale law, 1 represents the two elements are equally important. 3 represents the former element is slightly important. 5 represents the former element is more important.7 represents the former element is very important.9 represents the former element is absolutely important, and the other digits represent the importance between the numerical. 
(3) Consistency of judgment matrix

When compared to the various factors, it is impossible to be completely consistent because of the estimation error. In order to avoid the error is too large, we should test consistency of judgment matrix.

According to the judgment matrix, get the maximum eigenvalue and the corresponding eigenvector $\mathbf{A}=\left[a_{1}, a_{2}, \ldots, a_{n}\right]$. A reflects the importance ranking of each evaluation index, and that is the weight of each index.

We considered that when the judgment matrix satisfied consistency, it is fundamental reasonable that the conclusion based on AHP method. The test formula is shown below. CI means the degree of deviation from the consistency of the judgment matrix

$$
C I=\frac{\lambda_{\max }-f}{f-1}
$$

For different orders of the judgment matrix, the consistency error is different with the different demand value of CI. To 1-9 order judgment matrix, the value of RI are as Table 2.

Table 2. Mean random consistency index.

\begin{tabular}{cccccc}
\hline & 1 & 2 & 3 & 4 & 5 \\
\hline RI & 0.00 & 0.00 & 0.58 & 0.90 & 1.12 \\
\hline & 6 & 7 & 8 & 9 & \\
\hline RI & 1.24 & 1.32 & 1.41 & 1.45 & \\
\hline
\end{tabular}

$R I$ is the same order consistency index. When the order is greater than 2, the ratio of $C I$ to $R I$ is $C R$ that is the random consistency ratio. When $C R=C I / C R<0$, judgment matrix is consistent, and the weigh is the corresponding numerical in $\mathbf{A}$. When $C R=C I / C R \geq 0, \boldsymbol{A}$ need to adjust the value.

\subsection{Determine economic grade}

Determined the weight of each index, we should invite experts to grade these indexes.

In this paper, the fuzzy comprehensive evaluation method is adopted to deal with the scores of experts. Specific steps are as follows.

(1) Determine the evaluation factors and evaluation levels

$\mathbf{P}=\left\{p_{1}, p_{2}, \ldots, p_{m}\right\}$ is the set of evaluation factors. $p_{i}$ represents a evaluation index. $\mathbf{Q}=\left\{q_{1}, q_{2}, \ldots, q_{n}\right\}$ is evaluation level set. $q_{j}$ is factor evaluation level. $i \in[1, m], j \in[1, n]$.

(2) Establish the single factor fuzzy evolution, structure evaluation matrix $W$

Invite experts to evaluate the various factors $p_{i}$ in the set $\mathbf{P}$ in accordance with the set $\mathbf{Q}$ of $\mathbf{N}$ evaluation levels to judge. $p_{i}$ is the proportion of the total experts . $p_{i}$ consist of $w_{i(1 \times n)}$. After evaluating $\mathbf{M}$ factors, we can get judgment matrix $W$. $w_{i j}$ represents the grade of the factor $p_{i}$ can be subordinate to $q_{j}$.
$W=\left(w_{i j}\right)_{m \times n}=\left[\begin{array}{c}\mathbf{W}_{1} \\ \mathbf{W}_{2} \\ \vdots \\ \mathbf{W}_{m}\end{array}\right]$

(3) Fuzzy synthesis, get comprehensive evaluation vector $B$

Due to different ratio of the importance of each factor to the whole, each factor should be given a different weight. Based on the A get from AHP method, first class judgment is regarded as the second dimension layer to the main dimension layer on the base of fuzzy logic theory. The second class judgment is accumulation from the main dimension layer to object level, and get $B^{\prime}=\left(b_{k}\right)_{1 \times n}=W$ according to fuzzy matrix method. If $\sum b_{k}=1, B=B^{\prime}$. If $\sum b_{k} \neq 1, B=B^{\prime} / \sum b_{k}$. According to the principle of maximum membership principle, the corresponding evaluation level to the maximum value in $B$ is the grade of the evaluation object.

\section{EXAMPLE ANALYSIS}

Basic facilities of a medium charging station investment are 3,500, 000. Facilities investment is 800,000. Land acquisition costs are 300,000. There are 4 fast-charging piles and 16 AC charging piles. The medium charging station design operation period is 20 years. Annually operating costs is 400,000 (staff costs 20,000, equipment depreciation expense 100, 000, maintenance costs 100,000). Annual operating income is 630,000. Annual income and expenditure are increasing by $5 \%$. The income tax is $25 \%$, the discount rate is $3 \%$, and the project capital is equity capital.

By calculation, the static payback time is 15.84 years, ROI is $7.55 \%$, the net profit margin is $5.66 \%$, and IRR is $3.78 \%$.

\subsection{Fix weight}

The hierarchical structure model is constructed as shown in Figure 1 based on AHP in the second chapter.

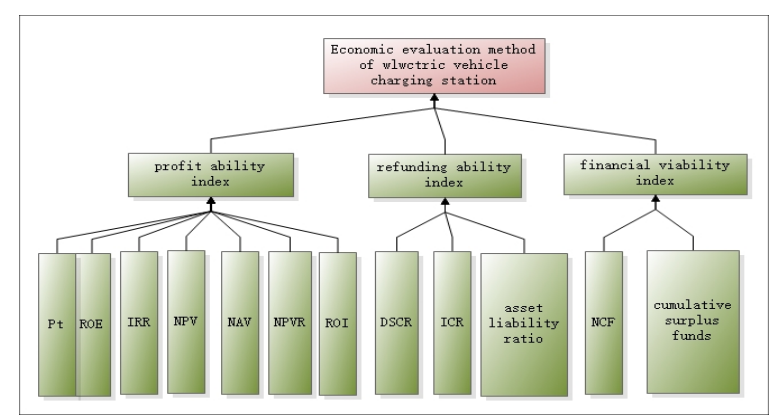

Figure 1. The hierarchical structure model 
Through the investigation of many experts, the comparison matrix is constructed aimed at various factors. After the expert scoring, the matrix E, E1, $\mathrm{E} 2$, E3 is determined as follows

$\mathbf{E}=\left[\begin{array}{cccc}e & e_{1} & e_{2} & e_{3} \\ e_{1} & 1 & 4 & 5 \\ e_{2} & 0.25 & 1 & 1 \\ e_{3} & 0.2 & 1 & 1\end{array}\right]$

$\mathbf{E}_{1}=\left[\begin{array}{cccccccc}e_{1} & e_{11} & e_{12} & e_{13} & e_{14} & e_{15} & e_{16} & e_{17} \\ e_{11} & 1 & 2 & 2 & 3 & 2 & 2 & 1 \\ e_{12} & 1 / 2 & 1 & 3 & 3 & 3 & 3 & 1 / 2 \\ e_{13} & 1 / 2 & 1 / 3 & 1 & 2 & 1 & 1 & 1 / 2 \\ e_{14} & 1 / 3 & 1 / 3 & 1 / 2 & 1 & 1 & 1 & 1 / 4 \\ e_{15} & 1 / 2 & 1 / 3 & 1 & 1 & 1 & 1 & 1 / 4 \\ e_{16} & 1 / 2 & 1 / 3 & 1 & 1 & 1 & 1 & 1 / 4 \\ e_{17} & 1 & 2 & 2 & 4 & 4 & 4 & 1\end{array}\right]$

$\mathbf{E}_{2}=\left[\begin{array}{cccc}e_{2} & e_{21} & e_{22} & e_{23} \\ e_{21} & 1 & 8 & 3 \\ e_{22} & 1 / 8 & 1 & 1 / 3 \\ e_{23} & 1 / 3 & 3 & 1\end{array}\right]$

$\mathbf{E}_{3}=\left[\begin{array}{ccc}e_{3} & e_{31} & e_{32} \\ e_{31} & 1 & 1 \\ e_{32} & 1 & 1\end{array}\right]$

After the calculation, the consistency ratio of the matrix $\mathbf{E}$ is 0.0053 , the consistency ratio of the matrix $\mathbf{E}_{1}$ is 0.0245 , the consistency ratio of the matrix $\mathbf{E}_{2}$ is 0.0015 ,and the consistency ratio of the matrix $\mathbf{E}_{3}$ is 0 .All above are less than 0.1,and are in accordance with conformance test.

The weight of first class index is $\mathbf{A}$. $\mathbf{A}=\left[\begin{array}{lll}0.6910 & 0.1602 & 0.1488\end{array}\right]$

The weight of second class to first class index are $\mathbf{A}_{1} 、 \mathbf{A}_{2} 、 \mathbf{A}_{3}$ respectively.
$\mathbf{A}_{1}=\left[\begin{array}{lllll}0.2153 & 0.1904 & 0.0959 & 0.0673 & 0.0788\end{array}\right.$
$\left.\begin{array}{ll}0.0788 & 0.2375\end{array}\right]$
$\mathbf{A}_{2}=\left[\begin{array}{lll}0.6816 & 0.0818 & 0.2366\end{array}\right]$
$\mathbf{A}_{3}=\left[\begin{array}{ll}0.5 & 0.5\end{array}\right]$

The weight of second class to the total weight of the whole are $\tilde{\mathbf{A}}_{1} 、 \tilde{\mathbf{A}}_{2} 、 \tilde{\mathbf{A}}_{3}$ respectively.
$\tilde{\mathbf{A}}_{1}=0.6910 \times \mathbf{A}_{1}=\left[\begin{array}{lll}0.1488 & 0.1316 & 0.0663\end{array}\right.$
$\left.\begin{array}{llll}0.0465 & 0.0544 & 0.0544 & 0.1890\end{array}\right]$

$\tilde{\mathbf{A}}_{2}=01602 \times \mathbf{A}_{2}=\left[\begin{array}{lll}0.1092 & 0.0131 & 0.0379\end{array}\right]$

$\tilde{\mathbf{A}}_{3}=01602 \times \mathbf{A}_{3}=\left[\begin{array}{ll}0.0744 & 0.0744\end{array}\right]$

The final weight coefficient of each index is shown in Table 3.
Table 3. Each index weight coefficient

\begin{tabular}{|c|c|c|}
\hline & First class index & second class index \\
\hline \multirow{23}{*}{$\begin{array}{c}\text { economic } \\
\text { evaluation } \\
\text { method of } \\
\text { electric } \\
\text { vehicle } \\
\text { charging } \\
\text { station } \\
1.0000\end{array}$} & \multirow{14}{*}{$\begin{array}{c}\text { charging station } \\
\text { profit ability index } \\
0.6910 \\
(0.6910)\end{array}$} & $\mathrm{Pt}$ \\
\hline & & $0.2153(0.1488)$ \\
\hline & & ROE \\
\hline & & $0.1904(0.1316)$ \\
\hline & & IRR \\
\hline & & $0.0959(0.0663)$ \\
\hline & & NPV \\
\hline & & $0.0673(0.0465)$ \\
\hline & & NAV \\
\hline & & $0.0788(0.0544)$ \\
\hline & & NPVR \\
\hline & & $0.0788(0.0544)$ \\
\hline & & ROI \\
\hline & & $0.2735(0.1890)$ \\
\hline & \multirow{5}{*}{$\begin{array}{c}\text { charging station } \\
\text { refunding ability } \\
\text { index } \\
0.1602 \\
(0.1602)\end{array}$} & DSCR \\
\hline & & $0.6816(0.1092)$ \\
\hline & & ICR \\
\hline & & $0.0818(0.0131)$ \\
\hline & & $\begin{array}{c}\text { Asset liability ratio } \\
0.2366(0.0379)\end{array}$ \\
\hline & \multirow{4}{*}{$\begin{array}{c}\text { charging station } \\
\text { financial viability } \\
\text { index } \\
0.1488 \\
(0.1488)\end{array}$} & NCF \\
\hline & & $0.5000(0.0744)$ \\
\hline & & cumulative curnlus \\
\hline & & $\begin{array}{l}\text { cumulative surplus } \\
\text { funds } 0.5000(0.0744)\end{array}$ \\
\hline
\end{tabular}

\subsection{Economic grade determination}

According to the charging stations, 20 experts grade the economy the base of 3 first class indexes, 12 second class indexes. There are 4 order of evaluation, best, good, moderate and worst.

$\begin{aligned} \mathbf{B}_{1} & =\left[\begin{array}{ccccc}e_{11} & 0.2 & 0.5 & 0.3 & 0 \\ e_{12} & 0.1 & 0.6 & 0.2 & 0.1 \\ e_{13} & 0.15 & 0.45 & 0.2 & 0.2 \\ e_{14} & 0.05 & 0.6 & 0.3 & 0.05 \\ e_{15} & 0.1 & 0.55 & 0.2 & 0.15 \\ e_{16} & 0.25 & 0.65 & 0.1 & 0 \\ e_{17} & 0.2 & 0.45 & 0.25 & 0.1\end{array}\right] \\ \mathbf{B}_{2} & =\left[\begin{array}{ccccc}e_{21} & 0.2 & 0.6 & 0.15 & 0.05 \\ e_{22} & 0.05 & 0.6 & 0.2 & 0.1 \\ e_{23} & 0.1 & 0.65 & 0.25 & 0\end{array}\right] \\ \mathbf{B}_{3} & =\left[\begin{array}{ccccc}e_{31} & 0.35 & 0.45 & 0.15 & 0.05 \\ e_{32} & 0.4 & 0.35 & 0.25 & 0\end{array}\right]\end{aligned}$

$\widetilde{\mathbf{B}}_{\mathbf{1}}=\mathbf{A}_{\mathbf{1}} \mathbf{B}_{\mathbf{1}}=\left[\begin{array}{llll}0.1621 & 0.5231 & 0.2341 & 0.0808\end{array}\right]$

$\widetilde{\mathbf{B}}_{\mathbf{2}}=\mathbf{A}_{\mathbf{2}} \mathbf{B}_{\mathbf{2}}=\left[\begin{array}{llll}0.1641 & 0.6118 & 0.1778 & 0.0423\end{array}\right]$

$\widetilde{\mathbf{B}}_{\mathbf{3}}=\mathbf{A}_{\mathbf{3}} \mathbf{B}_{\mathbf{3}}=\left[\begin{array}{lllll}0.3750 & 0.4000 & 0.2000 & 0.0250\end{array}\right]$

$\mathbf{B}^{\prime}=\left[\begin{array}{lll}\widetilde{\mathbf{B}}_{1} & \widetilde{\mathbf{B}}_{2} & \widetilde{\mathbf{B}}_{3}\end{array}\right]^{T}$ is the fuzzy judgment matrix first class index. 


$$
\begin{aligned}
& \widetilde{\mathbf{B}}^{\prime}=(\tilde{b})_{1 \times 4}=\mathbf{A B}^{\prime} \\
& =\left[\begin{array}{llll}
0.1941 & 0.5190 & 0.2200 & 0.0663
\end{array}\right] \\
& \mathbf{B}=\frac{\widetilde{\mathbf{B}}^{\prime}}{\sum \tilde{b}}=\left[\begin{array}{llll}
0.1942 & 0.5194 & 0.2201 & 0.0663
\end{array}\right]
\end{aligned}
$$

After normalization, the vehicle charging station comprehensive judgment vector is good based on the matrix B and principle of maximum membership principle. This result is in accordance with the IRR is $3.78 \%$ above. It is higher than the deposit rate. And it shows that the economic evaluation index of charging station is of practical significance.

\section{CONCLUSION}

This paper construct 12 second class indexes about the electric vehicle charging station from profit ability, refunding ability and financial viability. After calculation, this paper determined the weight of each index based on AHP, process the experts scoring scientific based on fuzzy comprehensive evaluation method, evaluate the operation economy of the electric vehicle charging station objectively. This paper established electric vehicle charging facilities evaluation index system combining with AHP and fuzzy comprehensive evaluation method. It provided an evaluation method for the future electric vehicle charging facilities planning and construction, and guided the development of the electric vehicle industry stably and orderly.

\section{ACKNOWLEDGEMENT}

This work is financially supported by Research Project of SGCC (YD71-15-032).

\section{REFERENCES}

B. Tian. 2012. Research on China's Electric Vehicle Scaled Development on Energy Structure [D]. China Academy of Fiscal Sciences.

C. Yu. 2010. Research on Project Risk Assessment for Green Automobiles Based on Risk Matrix [D]. Wuhan University of Technology.

C.H. Song. 2013. Economic Analysis and Policy Research of Jilin Province New Energy Automobile Industry [D]. Changchun University of Science and Technology.

F.Q. Zhou, Z.W. Lian, X.L. Wang, J.H. Yang \& Y.S. Xu. 2010. Discussion on Operation Mode to the Electric Vehicle Charging Station $[\mathrm{J}]$. Power System Protection and Control. 38(21):63-67.

J.L. Fan \& J. Liu. 2014. Research on Comprehensive Evaluation Method of Electric Vehicle Charging Pile [J]. Power System. 11:31-35.
J.G. Kang, Z.L. Wei, D.M. Cheng \& F. Xu. 2009. Research on Electric Vehicle Charging Mode and Charging Stations Construction [J]. Demand Side Management. 11(5):64-44.

M. Lu, X.B. Zhou \& W. Zhang. 2010. Research on Development of Charging Facilities for Electric Vehicles at Home and Abroad [J]. Central China Electric Power. 23(5):16-30

Q. Wang. 2012. Research of Impact on Power Grid and Operation Economics of Electric Vehicle Charging Station [D]. Shandong University.

T.T. Jiang. 2013. Study on Industrial Status and the Countermeasures Promotion of New Energy Vehicles [J]. Popular Science \& Technology.15 (9):173-174.

T. Xu, L.Zhang \& Y.L. Liang. 2011. Analysis on Energy Consumption Efficiency of Electric Vehicle and the Solutions to Improve the Energy Consumption Economy [J]. Energy Engineering. 02:1-5.

W.G. Zhang. 2013. Optimization Design and Economical Operation of Pure Electric Vehicles Swapping Station [D]. Beijing Jiaotong University.

W.J. Ge, M. Hang \& W.G. Zhang. 2013. Economic Operation Analysis of the Electric Vehicle Charging Station [J]. Transactions of China Electrotechnical Society. 28(2):15-21.

X.Q. Wang \& Y. Hang. 2015. Introduction and Enlightenment of Planning and Construction on Electric Vehicles Charging Infrastructure in Contemporary World [J]. Modern Urban Research. 01:107-116.

Y. Wang. 2011. Research on the Consumer's Purchase Intention of New Energy Vehicles Based on Perceived Risk and Involvement [D]. East China University of Science and Technology.

Y.H. Jin \& X.J. Li. 2012. Economic Analysis of New Energy Vehicles Based on PHEV and BEV of BYD [J]. Renewable Energy Resources. 30(6):118-126. 